\title{
“Eu Fiz um Aborto”: Os Blogues como Espaços de Manifesto
}

\author{
Caroline Matos Romio*, Adriane Roso, Larissa Goya Pierry, \& Anelize Saggin Alves \\ Universidade Federal de Santa Maria, Santa Maria, RS, Brasil
}

\begin{abstract}
RESUMO - Neste artigo, procuramos refletir sobre a experiência da interrupção voluntária da gestação das mulheres no Brasil e o modo como essa experiência se relaciona com os direitos sexuais e reprodutivos das mulheres. Para isso, realizamos uma pesquisa no espaço virtual, que foi utilizado como meio documental para a obtenção de relatos de mulheres que passaram pela experiência do aborto. Ao costurar os fragmentos dessas histórias, construímos saberes sobre a experiência de abortar, a qual, segundo a nossa leitura, pode ser dividida em três momentos temporais: momento da decisão pelo aborto; momento após a decisão e momento de cuidado. As mulheres, ao contarem suas histórias reprodutivas, falam de todas as mulheres, do tornar-se mulher no contexto histórico, social e cultural em que vivemos.
\end{abstract}

PALAVRAS-CHAVES: psicologia social, aborto, mulheres, internet

\section{“I Had an Abortion”: Blogs as Spaces for a Manifest}

\begin{abstract}
In this article, we sought to reflect on the experience of a voluntary interruption of pregnancy of women in Brazil and how this experience relates to the sexual and reproductive rights of women. In order to attain this objective, we used the Internet to collect accounts of women who have experienced an abortion. By examining these stories, we built an understanding on the experience of abortion. From our perspective, this experience can be divided in three moments: the moment of the decision (for the abortion), the moment after the decision, and the moment of care. Subsequently to these events, a different woman emerges. In this process, this woman identifies herself within the historical, social and cultural contexts in which we are inserted.
\end{abstract}

KEYWORDS: social psychology, abortion, women, internet

O tema do aborto voluntário, no contexto brasileiro, configura-se em um tabu, traz em si o sentido de algo inabordável, sendo, principalmente, expresso em proibições e restrições (Freud, 1913/2006). Estas produzem silenciamento, o que pode gerar sofrimento. Em oposição a elas, $\mathrm{o}$ ato de compartilhar experiências permite falar daquilo que tenciona e transborda. A fala possibilita a elaboração do sofrimento e a produção de novos sentidos. De fato, como mostrou Bülow (2004), a pessoa que sofre "percebe e compreende seu sofrimento de um modo novo quando divide suas experiências com outras pessoas que sofrem" (p. 20).

Sob esse aspecto, pensamos que a Psicologia tem muito a contribuir. A importância da escuta na Psicologia já foi enfatizada por diversos autores e campos teóricos (Elias \& Veras, 2008). A escuta sobre aborto "quer oportunizar, a partir da fala, um reposicionamento subjetivo" (Freire \& Chatelard, 2009, p. 1009) da mulher, frente a si mesma e aos outros.
Através do ato de compartilhar histórias escritas, como Jovchelovitch (2008) ressaltou, as representações do passado e as representações da identidade das mulheres ganham vida, junto com os saberes sociais. Falar sobre o aborto implica, portanto, compartilhar memórias, que, apesar de singulares, são também coletivas, por estarem inseridas em um contexto partilhado.

Conforme Corrêa e Petchesky (1996) e Boyle (1997), a partir dos movimentos feministas, os direitos sexuais e reprodutivos passaram a ter visibilidade e se tornaram parte essencial de uma ampla noção de Direitos Humanos. Esses direitos correspondem, para as mulheres, à possibilidade da tomada de decisões sobre seus corpos, sua sexualidade e suas escolhas reprodutivas.

Buscando conceituar, os direitos reprodutivos se referem às condições de exercício pleno, igual e livre das pessoas na esfera da vida reprodutiva (Ávila, 2003). Tais direitos implicam a possibilidade de escolha, por parte das mulheres,

*E-mail: carol.matosr@gmail.com 
sobre se e quando desejam procriar, destacamos, também, o direito de decidirem com quem e como procriar. Já os direitos sexuais implicam o exercício pleno, livre e igual da sexualidade, o que permite à mulher total direito sobre seu corpo, possibilitando a ela condições de recusa a relações sexuais indesejadas e inclusão da busca por prazer como parte dos seus direitos.

A efetivação de tais direitos, conforme Corrêa e Petchesky (1996), está atrelada à perspectiva de acesso a poder e recurso pelas mulheres. Nesse sentido, em consonância com Ávila (2003), a construção desses direitos integra-se ao movimento dialético de construção da democracia.

Também, nos debates acerca dos direitos sexuais e reprodutivos, o tema do aborto voluntário tem sido um dos mais polêmicos. A prática da interrupção voluntária da gestação é criminalizada em alguns países, como é o caso do Brasil. O Código Penal Brasileiro (1940) prevê que a praticante do aborto não será punida nos casos de gravidez resultante de estupro, nos casos de risco de vida à gestante $\mathrm{e}$, segundo Arguição do Supremo Tribunal Federal (2013), nos casos de fetos anencéfalos. Nesses países, as mulheres que decidem abortar realizam a prática sem condições de saúde e higiene, o que é definido como aborto inseguro, além de sofrerem forte coerção moral, esse cenário é reconhecido pelo Ministério da Saúde no documento Atenção humanizada ao abortamento: Norma técnica (2005).

Nesse contexto de coerção moral, a utilização do ciberespaço tem possibilitado expressões de resistência e articulação entre as mulheres frente ao contexto de criminalização do aborto. Entre as ferramentas do ciberespaço, destacamos os blogues por possuírem uma tecnologia relativamente fácil de uso e por estarem amplamente disponíveis.

Nesse sentido, os blogues têm potencial de se tornarem espaços alternativos às ideias dominantes (Cerqueira,
Ribeiro \& Cabecinhas, 2009). Segundo nossa compreensão, os blogues possibilitam a construção de uma rede de identificação entre as pessoas, pois, quando alguém posta um conteúdo, aquele que o acessa estabelece conexões com suas experiências de vida. A partir desse contexto, entendemos que os blogues, ao tratarem sobre a temática do aborto, oferecem um espaço mediador para o incremento da participação na esfera pública, o que é essencial para o desenvolvimento e a manutenção das democracias. Em suma, a comunidade fomenta a compreensão de si, produz a escrita, as narrativas e a busca por direitos.

No presente artigo, apresentamos parte de uma pesquisa que tem, como objetivo específico, refletir sobre a experiência da interrupção voluntária da gestação das mulheres no Brasil e o modo como essa experiência se relaciona com os direitos sexuais e reprodutivos das mulheres, utilizando o espaço virtual como meio documental para a obtenção de relatos de mulheres que passaram pela experiência do aborto induzido. Essa pesquisa integra uma dissertação denominada Aborto Induzido e Narrativas de Mulheres em Blogues, que está inserida no projeto de nível superior Sexualidades e Gênero/ Raça/Etnia: Estudo em representações, relações de poder e políticas públicas. Faz parte do grupo de pesquisa e extensão Saúde, Minorias Sociais e Comunicação e está vinculada ao Programa de Pós-Graduação em Psicologia da Universidade Federal de Santa Maria.

$\mathrm{Na}$ sequência do texto, apresentaremos a elaboração do corpus de análise, ou seja, como chegamos ao material textual que foi utilizado para pensar a relação entre aborto e direitos sexuais e reprodutivos e quais caminhos que esse material nos indicou. Posteriormente, desenvolvemos a análise dos resultados, esta foi composta por três momentos temporais: momento da decisão pelo aborto; momento após a decisão e momento de cuidado.

\section{CONSTRUINDO O CORPUS DE ANÁLISE}

A pesquisa foi desenvolvida visando a uma abordagem qualitativa, com delineamento exploratório (NascimentoSchulze, \& Camargo, 2000). Optamos pela realização da pesquisa em espaços virtuais, uma vez que essa configuração facilitaria o acesso às participantes, respeitaria a sensibilidade do tema e garantiria o seu anonimato, inclusive frente às pesquisadoras (Flick, 2009).

Diante disso, realizamos uma pesquisa documental no ciberespaço, utilizando fontes de documentos primários, escritas pelas próprias mulheres, ou seja, suas narrativas pessoais sobre os seus abortos voluntários postadas em sites. No entanto, ciente de que as narrativas provêm de humanos, a pesquisa foi previamente autorizada pelo Comitê de Ética da Universidade Federal de Santa Maria sob o número do CAE 28103814.7.0000.5346.
Optamos pelo não uso do consentimento informado, uma vez que a pesquisa envolveu observações naturalísticas em ambientes públicos, no caso a internet (Art. $6^{\circ}$, I, Resolução CFP $n^{\circ}$ 016/2000). Salientamos que os dados obtidos somente foram utilizados para fins de pesquisa.

Quanto aos procedimentos utilizados, a busca pelo material para a pesquisa ocorreu no mês de maio de 2014 . Enfatizamos que essa busca contou com duas etapas distintas: a primeira corresponde à seleção dos blogues e a segunda a inclusão das narrativas.

A primeira etapa consistiu na realização de duas buscas distintas, uma pelos termos: aborto AND relato e outra por aborto AND narrativa, no buscador Google $\mathbb{R}$ (versão brasileira), escolhido por corresponder ao mais popular e significativo site de buscas da internet, segundo Cruz e 
Hernándes (2008). Selecionamos, em cada uma das duas buscas, as 10 primeiras páginas de resultados do Google ${ }^{\circledR}$, contendo, cada uma delas, 10 sites ou blogues, o que totalizou 200 sites e blogues. Optamos por esse número para realizar uma restrição do material. Por serem multimídias, alguns sites indicavam o caminho para outros espaços virtuais com narrativas, que também foram incluídos na pré-seleção.

Percebemos que a maioria dos sites que continha as narrativas também possuía o formato de blogue e, por isso, optamos em selecionar apenas esse formato para análise. Quanto aos blogues selecionados, excluímos aqueles que possuíam venda de medicamento, também separamos um específico, que servirá para uma pesquisa futura, tendo ele como objeto de análise. Ao final dessa etapa, obtivemos um total de 10 blogues, que compuseram o corpus de análise da pesquisa.

Percebemos que, nesses espaços, aparecem debates sobre questões de gênero com frequência. Quatro espaços virtuais estão vinculados diretamente a coletivos, grupos e movimentos feministas. Um dos espaços se refere a uma revista eletrônica, que objetiva tratar do comportamento dos homens. Ainda, cinco dos blogues são espaços pessoais para apresentação e discussão de textos dos autores e, dos cinco, dois têm enfoque feminista e um enfoca a sexualidade das mulheres.

Após a etapa de seleção dos blogues, iniciamos a segunda etapa da pesquisa, que consistia na busca pelas narrativas. Para essa, realizamos pesquisas internas nos blogues, procurando narrativas que estivessem nas categorias de post, guest-posts ou comentários. Para serem incluídas na pesquisa, as narrativas deveriam corresponder aos critérios de inclusão da pesquisa, como narrativas escritas por quem realizou o aborto voluntário, que tivesse sido feito no Brasil de modo ilegal e que a autora do post não indicasse possuir menor idade legal na data em que relatou a experiência.
Por sabermos que o ciberespaço é impermanente, optamos pelo armazenamento dos textos obtidos no formato de documento de texto. Assim, construímos o corpus de análise composto por 57 narrativas sobre aborto, conforme a Tabela 1.

$\mathrm{O}$ material selecionado se restringiu às características textuais, imagens e vídeos vinculados aos textos foram desconsiderados para a análise das informações. A análise desenvolvida foi temática, de acordo com Flick (2009). A interpretação das informações obtidas com as narrativas tomou como base os pressupostos epistemológicos e ontológicos da Psicologia Social Crítica (Jovchelovitch, 2008; Marková, 2006), dando destaque ao que tange a discussão dos direitos sexuais e reprodutivos sob a égide das ideias desenvolvidas por feministas (Diniz, Dios, Mastrella, \& Madeiro, 2014; Motta, Tornquist, Miguel, \& Assis, 2010; Ávila, 2003; Boyle, 1997; Corrêa \& Petchesky, 1996; Barbosa \& Arilha, 1993).

Tabela 1. Distribuição das narrativas por blogues.

\begin{tabular}{lcc}
\hline Blogues* $^{*}$ & Número de Narrativas & Percentual \% \\
\hline Blogue 1 & 01 & 1,75 \\
Blogue 2 & 01 & 1,75 \\
Blogue 3 & 01 & 1,75 \\
Blogue 4 & 01 & 1,75 \\
Blogue 5 & 01 & 1,75 \\
Blogue 6 & 01 & 1,75 \\
Blogue 7 & 02 & 3,50 \\
Blogue 8 & 09 & 15,79 \\
Blogue 9 & 14 & 24,56 \\
Blogue 10 & 26 & 45,61 \\
Total & 57 & 100 \\
\hline
\end{tabular}

* Os nomes dos blogues e os endereços eletrônicos não serão divulgados para proteger o sigilo, o anonimato e a privacidade das participantes e das criadoras dos blogues.

\section{RELATANDO HISTÓRIAS, COMPARTILHANDO MEMÓRIAS}

Para se construir a análise, inicialmente numeramos as narrativas de 1 a 57, distribuídas de acordo com os blogues. Posteriormente, fizemos uma leitura atenta das 57 narrativas selecionadas, através da qual observamos a existência de uma relação direta entre a memória de cada mulher sobre a sua experiência em relação ao aborto e a história coletiva das mulheres e do aborto no Brasil.

O momento do aborto, escolhido pelas mulheres para ser contado através dos blogues, parece marcar suas trajetórias reprodutivas e, em alguns casos, suas identidades, enquanto mulheres capazes de decidirem sobre si. Ainda, o compartilhar histórias diz de um empreendimento coletivo, quando pessoas publicam suas histórias e se identificam com as demais histórias publicadas (Jovchelovitch, 2008).
Nas narrativas, observamos a tentativa de ordenar a experiência passada. Desse modo, optamos, na análise, pela utilização de três categorias, que são também categorias temporais. A primeira foi nomeada Momento da Decisão pelo Aborto, a segunda foi nomeada Momento após a Decisão, a terceira e última corresponde ao Momento de Cuidado.

Assim, foi elaborado um quadro de análise que facilitou a seleção do conteúdo de cada relato e, através dele, desenvolvemos uma lista de excertos das narrativas que foram utilizadas para ilustrar a análise. Ao final de cada excerto, indicamos o número do relato e o número do blogue do qual deriva. 
Entendemos que o material textual selecionado corresponde a narrativas pessoais, mas, por opção linguística das autoras das narrativas ou dos blogues, os textos são frequentemente nominados de relatos. Esta pode não ser uma escolha em vão, uma vez que narrar é descrever e tornar conhecida uma história, mas relatar é contar e carregar de volta uma história, referindo-se a uma retomada da memória (Nascentes, 1955).

Segue-se a análise dos relatos tendo em vista as categorias temporais. Cada categoria terá excertos em seu corpo textual, na tentativa de fazer dessa análise, também, uma costura de relatos.

\section{MOMENTO DA DECISÃO PELO ABORTO: DO SENTIMENTO DE CULPA À DELIBERAÇÃO DE NÃO SER MÃE NAQUELE MOMENTO}

Tratar da temática do aborto inclui abordar a sexualidade, a reprodução e a tomada de decisões pelas mulheres. $\mathrm{Na}$ experiência relatada por elas, entre o deparar-se grávida e a decisão pelo aborto, há a marca de um intervalo de tempo, que implica reflexões sobre os cuidados contraceptivos, sobre a maternidade enquanto uma escolha e a decisão de manter ou não o curso da gestação.

O período inicial, quando a mulher toma ciência que está grávida, frequentemente remete à experiência de um estranhamento com o corpo gestando. Esse estranhamento pode indicar uma não identificação com a maternidade em um dado momento: "Disse a eles que eu não o teria, nunca tive vontade de ser mãe, tenho, na verdade, bastante aversão a essa ideia. Fiquei desesperada" (Relato 35, Blogue 10).

Alguns relatos sinalizam que o estranhamento é acompanhado por sentimentos de vergonha que podem remeter ao local historicamente alocado à sexualidade das mulheres. Inicialmente, eram os discursos das religiões que instituíam um lugar limitado para o corpo das mulheres, já a partir do século XVIII, esses discursos se somaram aos saberes científicos emergentes que afirmavam que as mulheres apenas se "submeteriam" ao sexo com o intuito da maternidade, atividade pela qual se realizariam de modo pleno (Engel, 2000).

Tal representação permite uma dupla culpabilização das mulheres que desejam abortar. Primeiramente, essas mulheres têm desejos sexuais incompatíveis com a sua natureza, o que seria a expressão de uma anormalidade. Em seguida, a sexualidade manifestada necessitaria objetivar a maternidade, do contrário, desconsideraria justamente a atividade pela qual as mulheres mais deveriam ambicionar. Não à toa, nos discursos sobre aborto, a maternidade é frequentemente vista como a punição corretiva para os desvios sexuais da mulher:

Eu não queria ser mãe, mas tinha o medo, a vergonha de dizer que um método falhou, a criminalização não apenas do aborto, mas também do sexo sem compromisso praticado por mulheres, a sensação de ter cometido um erro e de ter que pagar a vida inteira por um erro com as pílulas. (Relato 54, Blogue 10)

Nesse cenário de culpabilização, as histórias costumam ser contadas, ora como confissão, que busca no leitor compreensão, ora como resistência, que espera do leitor mobilização para a transformação. Resistindo e refletindo, muitas narrativas iniciam falando sobre a contracepção e a responsabilização quase exclusiva das mulheres pelo planejamento reprodutivo: "Os métodos são falhos e, na maioria, voltados para as mulheres - DIU, Diafragma, pílula, injeções; há uma cultura que desresponsabiliza os homens pela tarefa da contracepção" (Relato 29, Blogue 6).

Essa cultura inviabiliza o princípio de igualdade dos direitos sexuais e reprodutivos, isso porque dentro de uma perspectiva de gênero, homens e mulheres possuem igual responsabilidade nos cuidados reprodutivos. Essa responsabilidade implica respeito ao outro, tomada de decisões em conjunto e compartilhamento dos cuidados sexuais e reprodutivos, tendo em vista equalizar as posições de homens e mulheres na sociedade.

Entretanto, segundo Corrêa e Petchesky (1996), há aqui uma contradição que merece destaque. Mesmo possuindo igual responsabilidade pelos cuidados reprodutivos, o corpo que engravida é o da mulher. Isso significa que a prática dos direitos sexuais e reprodutivos demanda olhar para a singularidade, compreender que mulheres e homens são diferentes e, nessa lógica, os direitos não podem ser tratados a partir de uma fórmula universal.

Ainda, alguns relatos ressaltam a limitação na eficácia dos métodos contraceptivos. Esse aspecto corrobora com as considerações da Organização Mundial da Saúde nos Critérios médicos de elegibilidade para o uso de métodos contraceptivos (2004). Segundo a OMS, todos os métodos contraceptivos possuem risco de falha no "uso perfeito", ainda, no "uso comum", suscetível a questões físicas, culturais e ambientais, esse risco é agravado: "Só que a única maneira 100\% segura de não engravidar é não fazer sexo, e aconteceu" (Relato 23, Blogue 9).

Também, riscos e falhas lembram o que é da ordem do humano. Mesmo com o ideal vigente de um corpo-máquina, com máximo desempenho e maior produtividade, esse corpo de ótimos resultados é essencialmente humano, passível de falhas e limitações. Desconsiderar isso abre margens para culpabilizar o humano por tudo aquilo que não o adequa ao sistema e, com isso, tirar da pessoa o que há de humano nela.

Finalizando a temática da contracepção, é preciso ponderar que, muitas vezes, o ato sexual não é acompanhado de medidas contraceptivas. Isso não apenas pode colocar em condições de vulnerabilidade o corpo, mas também fala da 
experiência humana de ser e vivenciar a sexualidade. Nesses casos, é preciso que as pessoas tenham acesso à informação, para que possam fazer escolhas conscientes e cuidar de seus corpos antes e após a prática: "Fazia tabelinha e sabia que naquele dia não podia, mas aconteceu e antes mesmo do dia da menstruação vir, comprei o exame e deu positivo. Entrei em pânico" (Relato 11, Blogue 2).

O excerto nos remete ao momento da constatação de estar gestando. Esse é um momento descrito recorrentemente e parece marcar a experiência do aborto. Segundo os relatos, os sentimentos frequentes vinculados com a descoberta da gravidez foram de tristeza, angústia e desorientação: "Sinto calafrios só de lembrar da angústia e desespero que tomaram conta de mim quando li 'positivo'naquele pedaço de papel" (Relato 15, Blogue 9).

Ainda, os relatos demonstram a incredulidade das mulheres diante da gravidez. Essa incredulidade é acompanhada de conjecturas vinculadas à experiência da gestação indesejada como algo que ocorre somente com outras mulheres: "Há dois anos atrás me descuidei. A gente sempre acha que essas coisas só acontecem com as 'outras"' (Relato 28, Blogue 5).

Essa percepção pode demonstrar um dos motivos pelos quais o tema do aborto parece não ser considerado socialmente. Ele fala do erro e da culpa do outro, um outro indefinido, com o qual a população, em geral, é pouco empática. $\mathrm{O}$ aborto é frequentemente pensado descontextualizado de um corpo e de uma história, esse pensamento costuma ser reforçado por posicionamentos dominantes que indicam ser o aborto errado e moralmente condenável, o que gera uma não implicação de todos com o tema.

Segundo Diniz, Medeiros e Madeiro (2017), aproximadamente uma em cada cinco mulheres irá realizar aborto ao longo da vida. Essas mulheres costumam pertencer a diferentes grupos sociais e religiosos, muitas são mães no momento que abortam ou virão a ser ao longo da vida.

Nos relatos, assim como Villarreal e Mora (1992) sinalizaram, encontramos as dificuldades econômicas como motivadoras frequentes para a realização do aborto. Também, há mulheres que sinalizam motivos subjetivos para a realização do aborto, como não se sentir preparada para criar um filho nesse momento, por questões profissionais ou pessoais, o que corrobora os estudos de Costa, Hardy, Osis e Faúndes (1995): "Lamento pelo filho que não se desenvolveu, mas tive que escolher entre a minha vida profissional e a maternidade" (Relato 03, Blogue 8); "Optei pelo aborto porque não tinha condições financeiras de educar uma criança" (Relato 03, Blogue 8).

Nos relatos, a decisão pelo aborto também é precedida por reflexões acerca da maternidade. Essas reflexões indicam que a percepção de estar grávida pode estar atrelada a uma não identificação com a maternidade naquele momento. Alguns deles, em consonância com os aspectos explorados por Boyle (1997), ressaltam o fato de que, para existir maternidade, é preciso um interesse da própria mulher a se vincular na tarefa de "ser mãe", não sendo isso um dado biológico, mas uma construção social: "Para cada dia que passava, eu ficava ainda mais apreensiva, chorava o tempo todo, não suportava a ideia de ser mãe, nunca foi meu desejo e meu namorado pensava da mesma forma" (Relato 07, Blogue 8).

Segundo Moura e Araújo (2004), tanto no Brasil, como na Europa, o estabelecimento da organização e dos sentimentos da família moderna, considerando aqueles relacionados à maternidade e aos cuidados maternos, teve influências da ascensão burguesa no final do século XVIII. Esse modelo surge como um dos alicerces do sistema capitalista, promovendo a preservação da propriedade privada através das relações monogâmicas e da criação nuclear dos filhos.

Para legitimar a família burguesa, estabelecem-se atribuições para as mulheres, que passam a ser responsáveis pelos comportamentos pessoais e familiares desejados. A mulher torna-se responsável pela gestação dos filhos legítimos, que devem ser criados e individualizados, a fim de serem adequados ao novo modelo de produção, que demanda mão-de-obra barata e livre. Ainda, para baratear o custo de reprodução do trabalho, faz-se essencial a contribuição invisível e não remunerada do trabalho doméstico das mulheres. Nesse contexto, a maternidade surge como o ideal natural de toda mulher (Soihet, 2000):

Já sofri muito por conta disso, mas acho que nós mulheres sofremos porque vivemos em uma sociedade opressora, que pretende delimitar quem nós devemos ser: mulheres exemplares, boas mães, ótimas companheiras. Nascemos para servir. E quando uma mulher toma uma decisão contrária a isso tudo, logo somos julgadas. (Relato 51, Blogue 10)

A compreensão do desejo maternal como natural em todas as mulheres vigora até os dias atuais. Boyle (1997) afirma que daí parte, em grande medida, a negação do aborto como um direito ou a percepção dele como algo nocivo para as mulheres. No entanto, pouco se fala sobre os aspectos físicos e emocionais negativos que podem advir da gestação: "Uma mulher pode gerar inúmeros fetos, mas um feto não desejado, só como feto, não gera nada além de dor, rejeição, traumas e infelicidade" (Relato 41, Blogue 10).

A compreensão da maternidade como desejo natural embasa a noção de que as mulheres não teriam condições morais e intelectuais para decidirem por si pelo aborto, daí, cabendo a necessidade da tutela do Estado. Desse modo, indagamos qual a função do judiciário em contextos de criminalização, uma vez que essa parece consistir na manutenção da vigência de um sistema de normas entendidas como universais e adequadas à sociedade, desconsiderando a existência de padrões alternativos: "Obrigar mulheres a ficarem na criminalidade quando algo devia ser direito, impor uma visão de mundo a todos, mesmo aqueles que 
pensam diferente, para mim esse é o crime mais feio e cruel!" (Relato 17, Blogue 9).

Refletindo sobre essa construção histórica da maternidade, destacamos o peso que a escolha do aborto tem na sociedade brasileira. Desse modo, pensar os direitos sexuais e reprodutivos inclui discutir sobre autonomia das mulheres para fazerem escolhas. Ainda nos perguntamos acerca do que é fazer escolhas em um sistema capitalista ou como tomar decisões em um sistema em que as possibilidades de escolhas são dadas a partir de "menus" configurados por esse sistema: "Minha escolha não gerou em mim nenhum sofrimento. O que foi sofrido é que ela não podia ser feita" (Relato 23, Blogue 9).

Diante disso, dialogar sobre os relatos implica pensar sobre o momento da decisão pelo aborto. Destacamos que essa é sempre uma experiência singular para cada mulher que a realiza e depende do momento no qual a mulher está vivendo.

$\mathrm{Na}$ leitura dos relatos, percebemos a autonomia como a capacidade de autodeterminação, a possibilidade de fazer escolhas para além dos "menus" em todas as esferas, inclusive na sexual e reprodutiva. Também inclui, conforme Petchesky (2000), na tomada de decisão, o acesso igual à cidadania e o respeito às particularidades individuais, além da garantia da integridade corporal.

$O$ fato de se perceber gestando e não desejar a maternidade, em um país onde o aborto é criminalizado, pode gerar sentimentos de angústia tão intensos que, algumas vezes, são acompanhados de pensamentos suicidas. Notamos a possibilidade de que a sensação de perda de controle sobre o próprio corpo gere sentimentos de desintegração, que, algumas vezes, são insuportáveis para a pessoa que os vive: "Meu pensamento, naquela hora, era de me matar" (Relato 09, Blogue 8).

Entretanto, há também os casos em que a decisão pelo aborto não condiz com uma escolha da mulher. Essas situações, ao irem de encontro aos direitos sexuais e reprodutivos, geram sofrimento para a mulher que as vive. Quando o parceiro ou a família decidem pelo aborto, há a demonstração de que é nas relações afetivas, dentro do espaço doméstico, que estão as mais violentas formas de coerção: "Fiz um aborto com 17 anos totalmente contra minha vontade, só para agradar minha mãe, que não queria dar satisfação de nossa vida (minha inclusa) para ninguém" (Relato 24, Blogue 9).

Percebemos que a deliberação pelo aborto encerra o Momento Anterior ao Aborto. Após a tomada de decisão, surge, para as mulheres, o desafio de buscar meios para realizar o aborto, que serão abordados na sequência: "Positivo novamente. Então começaria uma corrida contra o tempo para descobrir uma forma de fazer o aborto" (Relato 48, Blogue 10).

\section{MOMENTO APÓS A DECISÃO: REFLEXÕES SOBRE COMO ABORTAR}

O momento após a decisão pelo aborto é o mais detalhado pelas narrativas. Ele costuma ser composto pelas percepções de apoios e abandonos na decisão pelo aborto, no tempo da busca e escolha do método e também pela realização da prática em si.

Para se debater o tema da interrupção voluntária da gestação, é necessário refletir sobre as relações de gênero e poder. Isso porque, como lembrou Boyle (1997), apenas as mulheres abortam, entretanto, a regulação e o controle da prática é predominantemente determinada por homens: " $E u$ tenho certeza que se os homens engravidassem, o aborto seria legalizado há muito tempo. Quem domina os poderes, padres, bispos, parlamentares, pastores eles são a maioria dominante" (Relato 01, Blogue 1).

Segundo Ávila (2003), a relação dos homens frente à sexualidade e à reprodução costuma estar vinculada a um padrão de relações sociais forjadas sobre a desigualdade de gênero, ainda presente na atualidade. Esse padrão interfere na postura deles diante de uma gestação indesejada e da decisão de suas parceiras pelo aborto.

Observamos que estar acompanhada e obter apoio aparentam ser condições que diminuem os temores advindos da decisão pelo aborto. Em contrapartida, estar só amplia a experiência de dor. Dessa maneira, as narrativas são compostas pela integração das sensações de apoio e abandono. Podemos dizer que aqui aparece uma antinomia, que consiste na capacidade de dois conceitos, aparentemente duais, integrarem-se de modo não contraditório para se pensar um tema (Marková, 2006).

Essa dualidade parece estruturar o pensamento das mulheres acerca das suas experiências com o aborto. Segundo Marková (2006), podemos pensar que essa articulação através de um pensamento por antinomias visa a organizar as ideias e a comunicação em relação à experiência, permitindo a elaboração de um conhecimento social sobre o aborto.

A proposição de que cabe às mulheres a decisão última sobre a reprodução, haja vista que essa ocorre em seus corpos, em determinados casos, parece ter sido transformada em um argumento para que os homens se desresponsabilizem pelo processo de abortamento. Essa desresponsabilização, descrita pelas mulheres como abandono, foi observada tanto na total ausência do parceiro, quanto no apoio monetário restrito sem qualquer outra implicação: "Meu ex-namorado arcou com as despesas e lá fui eu tomar o remédio [...]. Não veio nem sequer me ver, nem ligou para saber como eu estava" (Relato 12, Blogue 3). 
Ainda, o abandono não se refere apenas às relações afetivas e sexuais, lembra também do olhar que o Estado destina às mulheres. Frequentemente, visualizamos uma ideologia que trata as mulheres e seus corpos como recursos de troca política: "O desespero é ainda maior quando você vê que não tem apoio do Estado para tirar aquilo de dentro de você, que [se] corre risco de vida e para piorar, que pode ser presa" (Relato 15, Blogue 9).

Outro aspecto relativo ao abandono se refere à postura de alguns profissionais de saúde, que adquirem o papel daqueles que julgam e/ou punem. Esse aspecto está presente nos serviços que realizam aborto previsto em lei no Brasil, onde a narrativa das mulheres sobre a situação de estupro é colocada em suspeição e a mulher precisa convencer os profissionais que possui traços subjetivos de vítima (Diniz et al., 2014). Isso vai contra as políticas de saúde brasileiras, conforme a Norma Técnica do Ministério da Saúde (2005), que propõem uma atenção à saúde humanizada, acolhedora e respeitosa: "Fui a uma consulta, disse ao médico que estava grávida e não queria levar adiante, só precisava de um pedido para o exame. A expressão dele me fez sentir horrivel" (Relato 35, Blogue 10).

Há também, na maioria das experiências descritas, a existência de figuras de apoio e cuidado, podendo ser os parceiros, amigos, mães, entre outros. Contar com relações de afeto e cuidado no momento da indução do aborto pode ser importante para a saúde emocional das mulheres: " $O$ pai do embrião entendeu que as consequências de qualquer escolha seriam vivenciadas, fisica e emocionalmente por mim e, como tal, apoiou minha opção" (23, Blogue 9).

Ainda, o tema do aborto pode integrar as mulheres. Isso se deve ao fato de ele configurar um segredo compartilhado, uma resistência às regras dominantes que, de um lado, responsabilizam as mulheres pela contracepção e, de outro, entretanto, criminalizam a interrupção da gestação. Isso está em consonância com os estudos prévios de Motta et al. (2010), que destacaram o fato de que o aborto envolve as mulheres em uma rede que produz saberes e práticas compartilhados: "Nunca quis ser mãe e as mulheres maravilhosas que me cercam sempre me apoiaram até mesmo nisso, o que, para mim, parecia uma atrocidade, elas explicaram que era mais do que natural" (Relato 49, Blogue 10).

Destacamos, ainda, a presença de profissionais da saúde que ofereceram apoio e escuta. Esses profissionais costumam ser descritos de duas formas: aqueles que auxiliaram no procedimento e os que respeitaram a decisão da mulher e se propuseram a prestar os cuidados de saúde posteriores:

[...] mas sempre dá pra contar com a generosidade de um médico, que acabou me arrumando uma quantidade necessária de comprimidos e ensinou como usar, bem como uma receita pra antibiótico e só me deixou alerta pro caso de sentir febre. (Relato 05, Blogue 8)

É claro que meu médico não apoiou a minha decisão, mas não interferiu, disse que se eu quisesse fazer, que fizesse, ele não poderia me orientar quanto a isso, me desejou boa sorte e disse que poderia ligar para ele quando tudo estivesse resolvido. (Relato 07, Blogue 8)

A percepção da rede de relações que a mulher possui pode facilitar ou dificultar a busca pelos recursos para abortar. Nessa busca, as mulheres irão se instrumentalizando em um contexto de ilegalidade. Ainda, se depararão com debates limitados sobre esse tema, que costumam estar envoltos em disputas morais, legais, culturais e sociais. Isso, entretanto, não inviabiliza que o aborto seja amplamente realizado, podendo ocorrer cerca de um milhão de abortos por ano no país, segundo documento do Ministério da Saúde acerca da Magnitude do Aborto no Brasil (2008).

Salientamos que, quando realizado por profissional competente e em condições adequadas de higiene, o aborto induzido apresenta poucos riscos para a mulher. Entretanto, quando ilegal, ele acaba sendo realizado de modo inseguro, o que apresenta risco de infecções e hemorragias. Em países em que o aborto induzido é criminalizado, o acesso à segurança costuma ser proporcional aos recursos econômicos que a mulher possui para despender nele, o que é evidenciado no documento Unsafe abortion (2011).

Desse modo, mesmo que seja singular, a experiência do aborto fala da possibilidade de acesso aos direitos sexuais e reprodutivos de todas as mulheres. Nos relatos, as autoras descrevem as deliberações sobre a escolha de como será realizado o aborto. Elas relatam a sensação de ansiedade e clandestinidade que acompanha a busca pelos recursos para abortar.

Devido ao silêncio das pessoas em relação à prática, a procura por informações costuma iniciar na internet, o que demonstra que o uso de ferramentas virtuais acompanha a experiência do aborto de um número significativo de mulheres no Brasil: "Com algumas pesquisas na internet (ainda bem que eu tinha acesso a ela) consegui informações sobre que remédio tomar, como tomar e até de como comprar" (Relato 41, Blogue 10).

Segundo os relatos, a escolha do método está vinculada ao acesso à informação, aos recursos econômicos e relacionais que a mulher dispõe. Destacamos a recorrência de dois métodos: o aborto induzido através de medicamento e o aborto realizado em clínica clandestina. Ainda, há tentativas com preparados de ervas, considerados menos eficientes que o medicamento, mas frequentemente associadas ao seu uso: "[...] eu tomei mais de 13 tipos de chá, e nada" (Relato 09, Blogue 8).

O meio mais relatado para indução do aborto foi a utilização de medicamento, o que está em consonância com outros estudos prévios que ressaltam o uso frequente do medicamento Cytotec $\AA$, princípio ativo misoprostol (Menezes, \& Aquino, 2009). Conforme a Anvisa (1998), esse medicamento tem seu uso restrito aos ambientes hospitalares no Brasil. No entanto, os relatos sinalizam para a existência de um comércio ilegal. O uso dessa medicação para a prática 
do aborto voluntário está associado com a diminuição de complicações decorrentes da prática, em detrimento de métodos mais invasivos (Borsari et al., 2012): "Comprei o Cytotec em frente à uma maternidade da minha cidade com um sujeito que tinha o apelido de Pastor" (Relato 17, Blogue 9).

As mulheres se deparam com alguns desafios na busca pelo medicamento, devido à proibição de sua comercialização. Há aí um cenário de clandestinidade que frequentemente expõe as mulheres a remédios falsificados e estelionatários. Elas precisam pagar e consumir uma droga ilegal, sabendo que a cada tentativa frustrada perde-se tempo e, em decorrência disso, reduzem as chances de realizar o procedimento e aumentam os riscos de complicações: "Fiz com cytotec também, caso dramático, comprei falso três vezes até achar o verdadeiro" (Relato 10, Blogue 8).

Durante o procedimento com medicamentos, as mulheres descrevem a presença de fortes cólicas seguidas de sangramento. Observamos que, além da difícil experiência de abortar sentindo dores, há o medo de ser punida, de estar exposta a complicações temendo buscar ajuda e, ainda, se deparar com os resquícios da interrupção da gestação. Ponderamos que o traumático de abortar também está nas adversidades decorrentes de sua realização em um cenário de criminalidade: “Gastei $R \$ 500$ com quatro comprimidos que me deram a pior experiência, em termos de dor, que já tive na vida" (Relato 02, Blogue 8); "Recolhia tudo que saía de mim, chorando de dor e de medo, suando frio" (Relato 07, Blogue 8).
Quando o Brasil trata uma questão de saúde como caso de polícia ou com moralismo, percebemos o quanto ainda está longe de ter uma legislação que empodere as mulheres e assegure seus direitos sexuais e reprodutivos. Nesse sentido, observamos que, quando providas de maiores recursos econômicos, as mulheres realizam abortos em clínicas.

Os relatos indicam a existência de clínicas clandestinas no Brasil, em que o procedimento é realizado de modo seguro, com um alto custo financeiro. O procedimento é descrito como rápido, acompanhado de anestesia, portanto indolor, além de seguro e limpo, no qual as mulheres se sentiram respeitadas e perceberam que sua saúde era preservada: "Hora marcada na clínica, segura, cara, em um bairro [...]. Fiz. Com toda segurança e respeito de que precisava naquele momento" (Relato 06, Blogue 8).

As condições seguras das clínicas, entretanto, não acabam com o medo advindo da criminalização da prática, pois, nos relatos, isso aparece como temor da polícia e de contaminação. Por ser ilegal, quem está abortando não possui garantias de que sua saúde será cuidada: “Ansiedade. Medo de dar tudo errado. Medo de aparecer polícia na clínica e ser presa" (Relato 20, Blogue 9); "Tive medo de usarem instrumentos cirúrgicos não esterilizados. Tive muito medo" (Relato 50, Blogue 10).

Percebemos que o momento após a decisão pelo aborto é marcado por fortes sentimentos e antagonismos que culminam com o encerramento da gestação. Após a experiência, as mulheres passam pelo momento de elaboração dela, o qual se definirá como o momento de cuidado.

\section{MOMENTO DE CUIDADO: ENCONTRANDO BRECHAS NO TABU}

As mulheres costumam descrever os sentimentos de retomada das suas vidas e dos seus corpos no momento final dos relatos. Inicialmente, esse momento é marcado pelo ato de se cuidar física e emocionalmente, composto pela busca de recursos que promovam bem-estar. Posteriormente, inclui os sentimentos referidos à realização da interrupção da gestação, o desfecho explicita reflexões advindas da experiência do aborto e da decisão de compartilhar suas histórias: "E emocionalmente falando, eu estava sim apreensiva que algo poderia dar errado e tinha medo de polícia e tudo mais só que quando o dr. disse que estava tudo bem, fiquei aliviada e esqueci do assunto" (Relato 05, Blogue 8).

Segundo Barbosa e Arilha (1993), um dos cuidados com a saúde mais recorrentes após o aborto induzido é a curetagem uterina. Esse procedimento é um dos utilizados pelos serviços de saúde para o tratamento de complicações decorrentes do procedimento abortivo, o que está em consonância com os relatos: "A médica [da cirurgia de curetagem] me explicou o que seria feito, respondeu com calma e sorrisos às minhas perguntas" (Relato 49, Blogue 10).
Ainda, para algumas mulheres, finalizar o aborto representa a retomada da autonomia sobre os seus corpos. Essa retomada é o retorno aos sentimentos de pertencimento de si e de identificação com o próprio corpo: "Meu corpo, minha mente, minha alma eram meus de volta" (Relato 06, Blogue 8).

O momento também inclui uma espécie de descarte de registros. O esforço de se desfazer de resquícios materiais do abortamento parece indicar uma tentativa de se livrar de possíveis provas da prática ilegal: "Minha amiga foi me buscar na internação e nós fizemos um 'mini ritual de bruxa' para nos livrarmos das evidências" (Relato 49, Blogue 10).

O momento posterior ao aborto também é marcado pelas reflexões das mulheres em relação à experiência. Alguns relatos descrevem sentimento de culpa e tristeza quanto à prática. Esses casos parecem estar associados a situações em que as mulheres não estavam certas de suas escolhas ou, ainda, em que elas possuíam percepções morais ou religiosas que as faziam se sentir praticantes de um pecado: "Me culpei, culpei o [parceiro], culpei o mundo por não ter me dado a oportunidade de conversar sobre o assunto, pensar em outras saídas" (Relato 20, Blogue 9). 
Em oposição, a maioria das narrativas descreve sentimento de alívio, felicidade e serenidade. Notamos que há uma aceitação muito grande das mulheres quanto à sua decisão, o que está de acordo com as indicações de Boyle (1997). Isso parece contradizer a tentativa do senso comum de associar o aborto a somente sofrimentos emocionais para as mulheres: "Estou feliz em não ter sido mãe" (Relato 44, Blogue 10).

Os relatos parecem estar em desacordo com o discurso comum de que aquela que realiza o aborto deve sentir-se culpada ou com remorso. Refletimos sobre a possibilidade que esse discurso seja uma estratégia para coibir a prática do aborto e o livre diálogo sobre ela. Reconhecemos, em consonância com Castro e Carril (2010), que há uma tendência, nos estudos sobre aborto e nos profissionais da saúde, em afirmar que o aborto é uma experiência traumática para a mulher, entretanto, os relatos demonstram o oposto: "Tenho a forte impressão que essa coisa de sentir-se culpada é só mais uma cobrança da sociedade [...]" (Relato 26, Blogue 9).

Ainda, os relatos indicam que o silêncio imposto em relação à interrupção da gestação gera sofrimento e é um tipo de violência. Poder compartilhar suas impressões, falar sobre o assunto e trocar informações foram indicados como meios que desagravam o desconforto diante da experiência vivida. Daí o significativo espaço que a psicologia pode ocupar ao acolher essas falas e promover a escuta, possibilitando reflexões sobre o tema: "Veio o sofrimento do silêncio. A proibição em falar sobre o aborto que eu fiz me colocava o peso da criminalidade" (Relato 48, Blogue 10).

$\mathrm{O}$ desfecho dos relatos parece indicar que as mulheres buscam compartilhar suas histórias, ao mesmo tempo em que também estão refletindo sobre o aborto, elaborando suas experiências, desmistificando a prática e construindo um entrelace de vivências que possibilita questionar a culpabilização e criminalização do aborto no Brasil: "Como eu acho extremamente importante desmistificar o aborto vou deixar meu relato aqui também" (Relato 05, Blogue 8).

Notamos, nos blogues, a união das mulheres na busca por estabelecerem uma rede de resistência diante de um sistema opressor, a fim de criarem mecanismos que lhes assegurem a oportunidade de falar sobre suas escolhas reprodutivas. A experiência do aborto parece aproximá-las em suas experiências de tornarem-se mulheres, de ter sua liberdade corporal restrita, de precisar se submeter a riscos para garantir sua autonomia, de necessitar resistir para ser ouvida: "Imagino o que passam as mulheres que todos os dias tomam chás duvidosos, enfiam agulhas de crochês nos seus úteros, confiam suas vidas a açougueiros de fundo de quintal, algumas sozinhas, sem ninguém para dar apoio" (Relato 28, Blogue 5).

\section{CONSIDERAÇÕES FINAIS}

O presente texto buscou refletir sobre a experiência da interrupção voluntária da gestação das mulheres no Brasil e o modo como essa experiência se relaciona com os direitos sexuais e reprodutivos das mulheres. Entendemos que essa reflexão contribui para pensar os aspectos subjetivos, emocionais e sociais vinculados à experiência do aborto. Aspectos esses que demonstram o importante espaço da psicologia nos estudos sobre o aborto no Brasil.

A pesquisa utilizou o espaço virtual como meio documental para a obtenção dos relatos de mulheres que passaram pela experiência do aborto induzido. A análise reforçou a consideração de que os espaços virtuais estão sendo utilizados pelas mulheres participantes como meios de "confissão", resistência e transformação, em que se pode falar e debater questões tidas como tabus pela sociedade, como é o caso do aborto. Ainda, compartilhar histórias permite a construção de uma comunidade, possibilitando a elaboração de um saber coletivo.

O momento do aborto, escolhido para ser compartilhado por meio dos blogues, marca as trajetórias sexual e reprodutiva das mulheres. Ele as coloca diante de questões como os direitos, recursos, acessos, apoios e poderes de que dispõem. Ainda, essa experiência é descrita de um modo temporal.
No Momento da Decisão pelo Aborto observamos a reflexão das mulheres sobre aspectos contraceptivos e conceptivos. Os relatos apresentam a necessidade de se questionar valores e perspectivas sociais que culpabilizam as mulheres pelo exercício de sua sexualidade e, ainda, refletem sobre o mito do desejo universal das mulheres pela maternidade.

No momento posterior à decisão, nominado de Momento após a Decisão, as mulheres se deparam com a necessidade de refletir sobre seus recursos relacionais. Nos relatos, é apresentado pela antinomia apoios e abandonos e configuram-se nas possibilidades de se sentir respeitada, acompanhada e acolhida. Após, há a busca pelo método abortivo, quando é preciso lidar com os dilemas de tomar uma decisão não aceita socialmente, nem legalmente.

Por fim, o Momento de Cuidado demonstra os cuidados com a saúde. Para algumas mulheres, esse momento sinaliza a retomada de seus corpos e de suas vidas. Ele é acompanhado pela elaboração subjetiva, o modo como a mulher sentiu a decisão e a experiência do aborto. Também apresenta, em seu desfecho, outras reflexões, como o questionamento da culpa como uma imposição social, o silêncio em torno da prática como uma violência e a necessidade de compartilhar histórias para construir redes de resistência e transformação social. 
Destacamos, como limitação da pesquisa, sua realização através de blogues, o que pode impossibilitar o acesso às mulheres com menos recursos tecnológicos e, talvez, econômicos. Outro aspecto se refere ao fato de que os relatos já se encontram prontos em ambientes virtuais, o que inviabiliza o diálogo com as autoras. Por outro lado, a pesquisa em espaço virtual abre espaço à Psicologia Social e outras áreas para acessar narrativas relacionadas a temas-tabu. Em territórios de (ainda) pouca censura, as "experiências de ilegalidade" podem aparecer sem que as mulheres tenham tanto receio de se abrirem umas com as outras.

Percebemos que o esforço das mulheres em falar sobre o aborto, questionar sua criminalização, debater os efeitos dessa prática realizada de modo inseguro, possibilita a ampliação do saber social sobre o tema. Também, pode apresentar recursos para se pensar a promoção dos direitos sexuais e reprodutivos. Destacamos que as mulheres, ao relatarem de si, de algum modo, falam de um episódio que compõe a trajetória sexual e reprodutiva de muitas mulheres, do tornar-se mulher num contexto histórico, social e cultural compartilhado, mas que é vivido de modo peculiar por cada sujeito.

Os relatos geram a percepção de que, para além dos debates teóricos, dos limites legais, existem mulheres vivendo a sua sexualidade e as suas decisões reprodutivas de modo marginal, clandestinas: "em resumo, sou clandestina porque transei, engravidei, não queria ser mãe e abortei" (Relato 33, Blogue 10). Por fim, depois de vivenciarem, são capazes de compartilhar suas histórias buscando transformar a realidade, afinal: "É simplesmente assim, sem eufemismos, sem rodeios, sem culpa e sem remorso que eu digo essa frase: eu fiz um aborto" (Relato 28, Blogue 5).

\section{REFERÊNCIAS}

Arguição de Descumprimento de Preceito Fundamental Número 54. (2013). Brasília: Supremo Tribunal Federal.

Atenção humanizada ao abortamento: Norma técnica. (2005). Brasília: Ministério da Saúde.

Ávila, M. B. (2003). Direitos sexuais e reprodutivos: Desafios para as políticas de saúde. Cadernos de Saúde Pública, 19(suppl 2), S465-S469.

Barbosa, M. G., \& Arilha, M. (1993). A Experiência brasileira com o Cytotec ${ }^{\circledR}$. Estudos Feministas, 1(2), 408-417.

Borsari, C., Nomura, R., Benute, G., Nonnenmacher, D., Lucia, M., \& Francisco, R. (2012). O aborto inseguro é um problema de saúde pública. Femina, 40(2), 63-68.

Boyle, M., (1997). Re-thinking abortion: Psychology, gender, power and the law. Londres: Routledge.

Bülow, P. (2004). Sharing experiences of contested illness by storytelling. Discourse \& Society, 15(1), 33-53.

Castro, R., \& Carril, E. (2010). Aborto, professionales de la salud y derechos reproductivos. In R. Castro \& A.L. Gómez (Eds.), Poder Médico y Ciudadanía: el conflito social de los profesionales de la salud com los derechos reproductivos em América Latina (pp. 29-48). Montevideo: Universidad de La República.

Cerqueira, C., Ribeiro, L. T., \& Cabecinhas, R. (2009). Mulheres \& Blogosfera: Contributo para o estudo da presença feminina na "rede". Ex Aequo, 19, 111-128.

Código Penal Brasileiro. (1940). Decreto-Lei Número 2.848, de 7 de Dezembro de 1940. Brasília.

Corrêa, S., \& Petchesky, R. (1996). Direitos sexuais e reprodutivos: Uma perspectiva feminista. Physis: Revista de Saúde Coletiva, 6(1-2), 147-177.

Costa, R. G., Hardy, E., Osis, M. J. D., \& Faúndes, A. (1995). Adecisão de abortar: Processo e sentimentos envolvidos. Cadernos de Saúde Pública, 11(1), 97-105

Critérios médicos de elegibilidade para o uso de métodos anticoncepcionais. (2004). Genebra: Departamento de Saúde Reprodutiva e Pesquisa, Organização Mundial da Saúde.

Cruz, Y., \& Hernandez, A. (2008). Cuil, ¿la competencia de Google? Una evaluación desde el punto de vista documental. ACIMED, 18(6), 1-9.
Diniz, D., Dios, V. C., Mastrella, M., \& Madeiro, A. P. (2014). A verdade do estupro nos serviços de aborto legal no Brasil. Revista Bioética, 22(2), 291-298.

Diniz, D., Medeiros, M., \& Madeiro, A. (2017). Pesquisa Nacional de Aborto 2016. Ciência \& Saúde Coletiva, 22(2), 653-660.

Elias, G. G. P., \& Veras, M. O. (2008). Psicologia escolar: Abrindo espaço para a fala, a escuta e o desenvolvimento interpessoal. Revista da Abordagem Gestáltica, 14(2), 182-189.

Engel, M. (2000). Psiquiatria e feminilidade. In M. D. Priore, (Ed.), História das mulheres no Brasil (pp. 270-304). São Paulo: Contexto.

Flick, U. (2009). Introdução à pesquisa qualitativa (3rd ed.). Porto Alegre: Artmed.

Freire, T. C. G., \& Chatelard, D. S. (2009). O aborto é uma dor narcísica irreparável? Revista Mal-Estar e Subjetividade, 9(3), 1007-1022.

Freud, S. (2006). Totem e tabu e outros trabalhos. Rio de Janeiro: Imago. (Original publicado em 1913)

Jovchelovitch, S. (2008). Os contextos do saber: Representações, comunidade e cultura. Petrópolis: Vozes.

Magnitude do aborto no Brasil. Aspectos epidemiológicos e sócio-culturais. Abortamento previsto em lei em situações de violência sexual (2008). Brasília: Ministério da Saúde.

Marková, I. (2006). Dialogicidade e representações sociais: As dinâmicas da mente. Petrópolis: Vozes.

Menezes, G., \& Aquino, E. (2009). Pesquisa sobre o aborto no Brasil: Avanços e desafios para o campo da saúde coletiva. Caderno de Saúde Pública, 25(2), s193-s204.

Motta, F. M., Tornquist, C. S., Miguel, D. S., \& Assis, G. de O. (2010). "Não me sinto culpada": Práticas contraceptivas e aborto em grupos populares urbanos. In C. Rial, J. M. Pedro, \& S.M.F. Arend (Eds.), Diversidade: Dimensão de gênero e sexualidade (pp. 251-267). Florianópolis: Mulher.

Moura, S. M. S. R., \& Araújo, M. F. (2004). A maternidade na história e a história dos cuidados maternos. Psicologia: Ciência e Profissão, 24(1), 44-55.

Nascentes, A. (1955) Dicionário etimológico da língua portuguesa. Rio de Janeiro: Livraria Acadêmica. 
Nascimento-Schulze, C., \& Camargo, E. (2000). Psicologia social, representações sociais e métodos. Temas em Psicologia, 8(3), 287-299.

Petchesky, R. (2000). Rights and needs: Rethinking the connections in debates over reproductive and sexual rights. Health and Human Rights, 4(2), 17-29.

Portaria 344 de 12 de maio de 1998. (1998). Brasília: Agência Nacional de Vigilância Sanitária.

Resolução CFP n $n^{\circ}$ 016/2000 de 20 de dezembro de 2000. Dispõe sobre a realização de Pesquisa em Psicologia com Seres Humanos (2000). Brasília: Conselho Federal de Psicologia.

Soihet, R. (2000). Mulheres pobres e violência no Brasil urbano. In M. D. Priore (Ed.), História das mulheres no Brasil (pp. 304-335). São Paulo: Contexto.
Unsafe abortion: Global and regional estimates of the incidence of unsafe abortion and associated mortality in 2008 (2011). Genebra: World Health Organization.

Villarreal, J. M., \& Mora, M. T. (1992). Embarazo indeseado y aborto: Determinantes de la lnterrupción del embarazo no deseado y características de las mujeres que abortam. Oriéntame. Bogotá: Editorial Presencia.
Submetido: 02/07/2015

Revisado: 22/03/2018

Aceito: 23/04/2018 